\title{
The use of navy C-ring specimens to study distortion in ferritic nitrocarburized 1010 steel
}

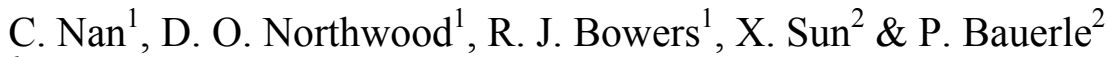 \\ ${ }^{I}$ Department of Mechanical, Automotive and Materials Engineering, \\ University of Windsor, Canada \\ ${ }^{2}$ Chrysler LLC, USA
}

\begin{abstract}
Ferritic nitrocarburizing is being proposed as an alternative to gas carbonitriding to improve the surface characteristics of SAE 1010 plain carbon steel automotive components without producing unacceptable part distortion. Navy C-rings are specially designed specimens for the evaluation of the distortion (size and shape) that result from any heat treatment process. In this study, gas ferritic nitrocarburizing and nitrogen cooling was used to heat treat Navy C-ring specimens of varying thicknesses $(2.8 \mathrm{~mm}-19.05 \mathrm{~mm})$ at temperatures ranging from $510^{\circ} \mathrm{C}$ to $595^{\circ} \mathrm{C}$. For each combination of part thickness and heat treatment temperature, the following parameters were evaluated: size and shape distortion; XRD and OM (optical microscopy) to characterize the nature of the nitride layers formed at the surface; X-ray determination of the residual stresses in the nitride surface layers.

The various combinations of nitrocarburizing temperature and time resulted in an expansion of the OD (Outside Diameter) dimension and a small deterioration in flatness. The ID (Inside Diameter) changed from a small expansion $(+0.02 \%)$ for the thickest specimens $(19.05 \mathrm{~mm})$ to a small contraction $(-0.02 \%)$ for the thinnest specimens $(2.8 \mathrm{~mm})$. The gap tends to close up as the thickness decreases from the thickest to the thinnest specimens. Microstructural differences were found in the nitrided layers formed at the different heat treatment temperatures. The residual stresses in the outer $\varepsilon$-nitride layers $\left(\mathrm{Fe}_{3} \mathrm{~N}\right)$ were typically tensile. On the basis of these results, preliminary recommendations are made as to heat treatment parameters to lower distortion.
\end{abstract}

Keywords: navy C-ring, ferritic nitrocarburizing, carbonitriding, dimensional distortion, residual stress. 


\section{Introduction}

Carburizing and carbonitriding have become important and widely used processes for developing hard cases at the surface of steel parts by modifying the chemical composition of the surface with hardening species such as carbon and nitrogen [1]. Carbonitriding is generally regarded as a modified gas carburizing process, in which nitrogen is introduced into the gas carburizing atmosphere through the dissociation of ammonia, and diffuses into the austenite of steel simultaneously with carbon [2,3]. Similar to carburizing, the austenite composition is changed and high surface hardness is produced by quenching to form martensite [4]. However, carbonitriding is performed at lower temperatures ranging between 705 and $900^{\circ} \mathrm{C}$ and shorter times than carburizing. The reduced process time and temperature, in addition to the ability of nitrogen to inhibit the diffusion of carbon, results in relatively shallow case depths, from 0.075 to $0.75 \mathrm{~mm}[2,4]$.

The nitrogen in carbonitrided steels enhances the hardenability of steel by lowering the critical cooling rate, and improves the resistance of steel to softening at slightly elevated temperatures [2]. However, high nitrogen levels can result in retained austenite after quenching because nitrogen lowers the transformation temperature of austenite, and can lead to the formation of voids or porosity when processing times are too long $[2,3]$. The delayed transformation of austenite to martensite at ambient temperatures can be extremely detrimental as it results in both size and shape distortions which may cause serious assembly issues as binding or "freezing" in components with high tolerance specifications [2].

Ferritic nitrocarburizing is another surface hardening method that involves the diffusion of both nitrogen and carbon to the surface of steel while it is in the ferritic condition [5], usually at temperature range between 525 and $650^{\circ} \mathrm{C}$ [6]. When a steel is nitrocarburized, two different structures, known as the compound layer and diffusion region, can be developed from the surface to the core of the steel [7]. The very thin compound layer with thickness usually between 10 and $40 \mu \mathrm{m}$ for most applications is composed of single-phase epsilon ( $\varepsilon$ ) ironcarbonitride $\left(\mathrm{Fe}_{2-3}(\mathrm{~N}, \mathrm{C})\right)$, forming between 450 and $590^{\circ} \mathrm{C}$ [8]. The diffusion zone beneath the compound layer contains varying amounts of gamma prime $\left(\gamma^{\prime}\right)$ and epsilon phase, cementite, and various alloy carbides and nitrides [8,9]. The compound layer improves the tribological properties, wear and corrosion resistance, while the diffusion zone increases the fatigue endurance limit, particularly in carbon and low-alloy steel $[5,10]$. The total thickness of the compound layer and the diffusion zone can reach $1 \mathrm{~mm}$ [8]. Another advantage of ferritic nitrocarburizing is the minimum distortion due to the low-temperature process, no subsequent transformation from austenite to martensite occurs [6].

In the present study, gas ferritic nitrocarburizing and nitrogen cooling was performed at different heat treatment temperatures and times as well as a carbonitriding using current production practice for 1010 steel automotive components [11]. Navy C-ring specimens with varying thicknesses were used to 
evaluate the size and shape distortion, the microstructure and the surface residual stresses produced by different heat treatment parameters [12].

Residual stresses are the inevitable result of thermomechanical processing of steel [13]. With its high spatial resolution and speed, excellent accuracy and nondestructive measurements, X-ray diffraction (XRD) has become an essential tool for residual stress determination. The presence of residual stress in the material causes a shift in the XRD peak angular position that can be directly measured. The depth of X-ray penetration in a material is dependent on the wavelength of the incident radiation and the mass absorption coefficient of the material. Common depths of penetration range between 10 and $20 \mu \mathrm{m}$ [14].

\section{Experimental details}

The Navy C-ring specimens were cut from bar stock of hot rolled SAE 1010 plain carbon steel. The chemical composition of the steel is given in Table 1.

Table 1: $\quad$ Chemical composition of SAE 1010 plain carbon steel.

\begin{tabular}{|c|c|c|c|}
\hline Element & Wt. $\%$ & Element & Wt. \% \\
\hline Carbon & 0.12 & Aluminum $(\mathrm{Al})$ & 0.052 \\
\hline Manganese $(\mathrm{Mn})$ & 0.43 & Vanadium (V) & 0.001 \\
\hline Phosphorus & 0.008 & Columbium $(\mathrm{Cb})$ & Not Detected \\
\hline Sulfur & 0.008 & Titanium & 0.002 \\
\hline Silicon & 0.03 & Cobalt & Not Detected \\
\hline Chromium & 0.03 & (Sn) & Not Detected \\
\hline Nickel & 0.01 & Boron & 0.0003 \\
\hline Molybdenum (Mo) & 0.01 & Calcium & 0.0001 \\
\hline Copper & 0.02 & Zirconium $(\mathrm{Zr})$ & Not Detected \\
\hline Plumbum & Not Detected & Tungsten & Not Detected \\
\hline
\end{tabular}

The dimensions of the Navy C-rings are shown in Figure1. According to their thickness (19.05 to $2.8 \mathrm{~mm}$ ), the Navy C-rings were divided into five groups identified as the 1-NC to 5-NC series. Each of these groups was again subdivided into two groups. One group underwent gas ferritic nitrocarburizing and a subsequent nitrogen cooling process. The other group was heat treated using a gas carbonitriding and oil quench process. The detailed heat treatment parameters are given in Table 2. Each heat treatment process schedule was identified using the symbols $a$ to $e$.

Four specified dimensions for each C-ring sample were measured using a Coordinate Measuring Machine (CMM) both before and after heat treatment. These dimensions were OD, ID, gap width and surface flatness. These results were then used to compare both size (OD, ID, gap) and shape (flatness) distortion for the different heat treatment processes. 


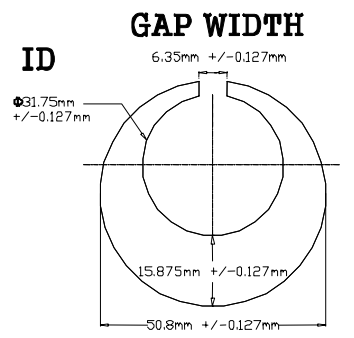

OD

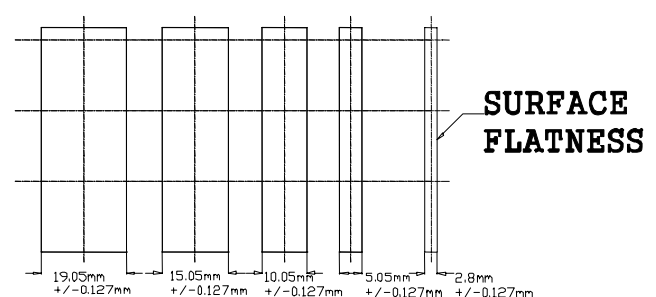

THICKNESS

Figure 1: Navy C-ring's geometry and distortion measurement positions.

Table 2: $\quad$ Heat treatment processing matrix for navy C-ring specimens.

\begin{tabular}{|c|c|c|c|c|c|}
\hline \multirow{2}{*}{ No. } & \multicolumn{5}{|c|}{ Heat treatment schedule } \\
\hline & \multicolumn{2}{|c|}{ Process 1} & \multicolumn{2}{|c|}{ Process 2} & Symbol \\
\hline 1 & \multirow{4}{*}{$\begin{array}{c}\text { Gas ferritic } \\
\text { nitrocarburizing }\end{array}$} & $510^{\circ} \mathrm{C} / 15 \mathrm{hrs}$ & \multirow{4}{*}{$\begin{array}{l}\text { Nitrogen } \\
\text { cooling }\end{array}$} & \multirow{4}{*}{$425^{\circ} \mathrm{C}$} & $a$ \\
\hline 2 & & $540^{\circ} \mathrm{C} / 10 \mathrm{hrs}$ & & & $b$ \\
\hline 3 & & $565^{\circ} \mathrm{C} / 5 \mathrm{hrs}$ & & & $c$ \\
\hline 4 & & $595^{\circ} \mathrm{C} / 4 \mathrm{hrs}$ & & & $d$ \\
\hline 5 & Gas carbonitriding & $850^{\circ} \mathrm{C} / 4 \mathrm{hrs}$ & Oil quench & $100^{\circ} \mathrm{C}$ & $e$ \\
\hline
\end{tabular}

An XRD method was used to determine the residual stress on the surface of nitrocarburized C-ring samples. The measurement location of the residual stress was at the thickest section of the OD. The alignment of the XRD instrument was performed according to the ASTM E915 Standard [15]. The residual stresses were calculated by measuring the lattice deformations on the (302) crystallographic plane of the $\varepsilon$-phase $\left(\mathrm{Fe}_{3} \mathrm{~N}\right)$ using $\mathrm{Cr}$ target with a wavelength of $0.2291 \mathrm{~nm}$. The generator voltage and current settings were $40 \mathrm{kV}$ and $40 \mathrm{~mA}$, respectively. The Bragg angle $(2 \theta)$ was set at $165.00^{\circ}$. The following $\Psi$ angles were used to ensure accurate residual stress results: $0^{\circ}, \pm 30.00^{\circ}, \pm 23.46^{\circ}$, $\pm 11.95^{\circ}$, and $\pm 7.58^{\circ}$. A detailed description of the XRD residual stress analysis method is given in references $[13,14,16]$.

\section{Results and discussion}

\subsection{Optical metallography}

A series of micrographs for the nitrocarburized 5-NC C-ring samples are shown in Figures 2-5. The white layer is formed as a relatively uniform band at the surface. X-ray structural analysis revealed that the layer is composed predominantly of the $\varepsilon$ phase. Beneath the white layer is the diffusion zone, which consists of a needle-like $\gamma^{\prime}$ phase. As shown in Figure 2, the $\gamma^{\prime}$ phase is mainly located near the interface of compound layer and diffusion zone. The 


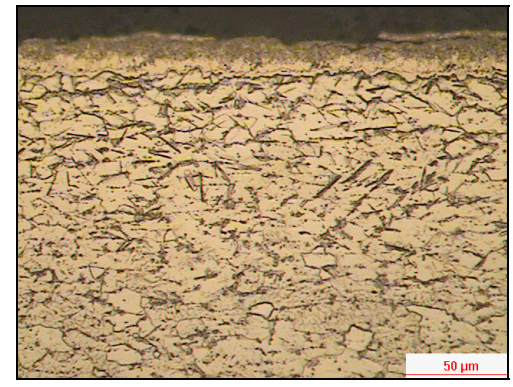

Figure 2: Microstructure of the gas ferritic nitrocarburized sample $(a)$.

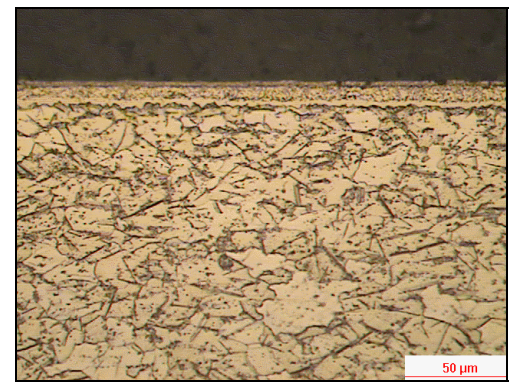

Figure 4: Microstructure of the gas ferritic nitrocarburized sample (c).

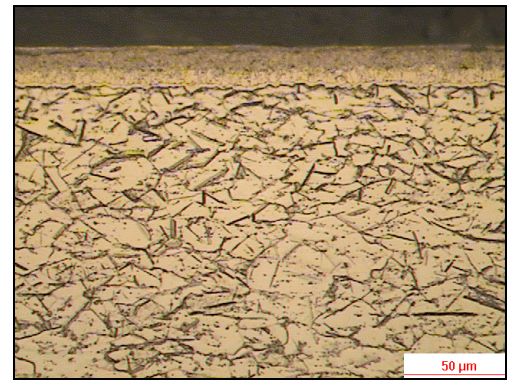

Figure 3: Microstructure of the gas ferritic nitrocarburized sample $(b)$.

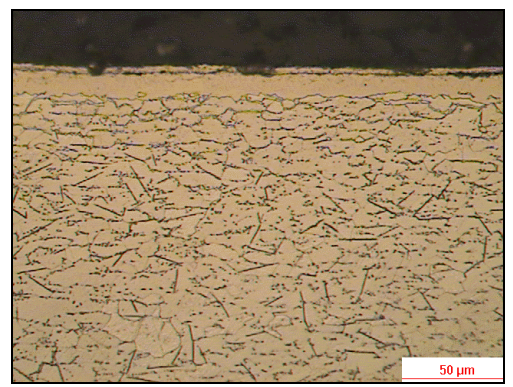

Figure 5: Microstructure of the gas ferritic nitrocarburized sample $(d)$.

penetration of $\gamma^{\prime}$ in the diffusion zone increased with increasing temperature, as illustrated in Figures 3-4.

\subsection{Comparison of size and shape distortion}

The dimensional measurements for the various C-ring sample groups were repeated on 10 identically treated C-rings, the averages of the values obtained from the individual tests were then reported as percentage dimensional changes, and are shown in Tables 3-5.

Both nitrocarburizing and carbonitriding led to a small expansion of the outside diameter, except for the carbonitrided 5-NC sample. Gas carbonitriding produced the largest OD distortion in the 1-NC series. A comparison of the OD changes resulting from the different ferritic nitrocarburizing processes is shown in Figure 6. The OD changes were similar in the same series (thickness) of specimens for the different nitrocarburizing temperatures. A comparison of the different C-ring series reveals that the OD dimensions of 1-NC and 5-NC series varied over a wider range from sample to sample and with temperature: this was 
particularly true for the thinnest samples (5-NC series). The $565^{\circ} \mathrm{C} / 5$ hours process resulted in the smallest OD change compared to the other temperature time combinations.

Table 3: $\quad$ OD size distortion of C-ring samples (unit: \%).

\begin{tabular}{|c|c|c|c|c|c|}
\hline Process & 1-NC series & 2-NC series & 3-NC series & 4-NC series & 5-NC series \\
\hline$a$ & 0.0509 & 0.0418 & 0.0472 & 0.0472 & 0.0541 \\
\hline$b$ & 0.0463 & 0.0374 & 0.0409 & 0.0360 & 0.0549 \\
\hline$c$ & 0.0438 & 0.0383 & 0.0440 & 0.0340 & 0.0380 \\
\hline$d$ & 0.0491 & 0.0393 & 0.0463 & 0.0336 & 0.0548 \\
\hline$e$ & 0.1146 & N/A & N/A & 0.0295 & -0.0195 \\
\hline
\end{tabular}

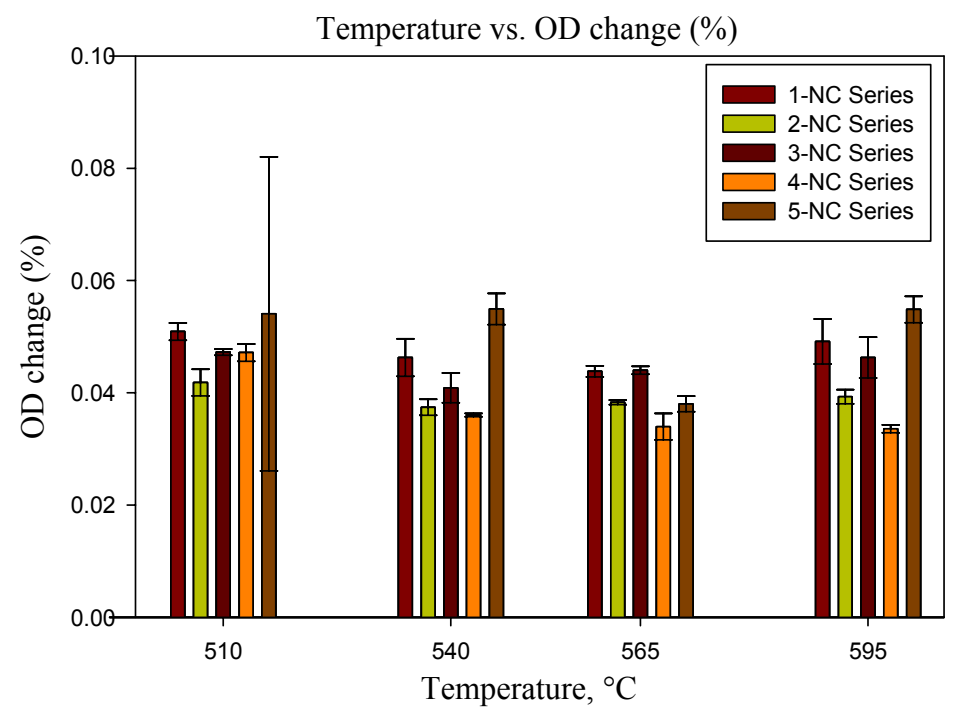

Figure 6: OD change of nitrocarburized C-rings as a function of nitrocarburizing temperature.

Table 4: $\quad$ ID size distortion of C-ring samples (unit: \%).

\begin{tabular}{|c|c|c|c|c|c|}
\hline Process & 1-NC series & 2-NC series & 3-NC series & 4-NC series & 5-NC series \\
\hline$a$ & 0.0203 & 0.0009 & 0.0009 & -0.0216 & 0.0166 \\
\hline$b$ & 0.0248 & 0.0008 & 0.0004 & -0.0087 & -0.0209 \\
\hline$c$ & 0.0201 & 0.0029 & 0.0012 & -0.0108 & -0.0079 \\
\hline$d$ & 0.0213 & -0.0038 & 0.0018 & -0.0070 & -0.0156 \\
\hline$e$ & 0.1565 & N/A & N/A & -0.0343 & -0.1230 \\
\hline
\end{tabular}

For the ID measurements shown in Table 4, the C-rings subjected to gas carbonitriding experienced larger ID changes than those subjected to ferritic nitrocarburizing. The ID dimension after nitrocarburizing increased in the 1-NC 
series, whereas it decreased in the 4-NC series. The 2-NC and 3-NC series showed smaller ID changes than the other series, see Figure 7. Similar to the OD results, the 1-NC and 5-NC series showed larger ID distortion than the other series. The ID dimension of the 5-NC series varied widely from sample to sample after 15 hours heat treatment at $510^{\circ} \mathrm{C}$.

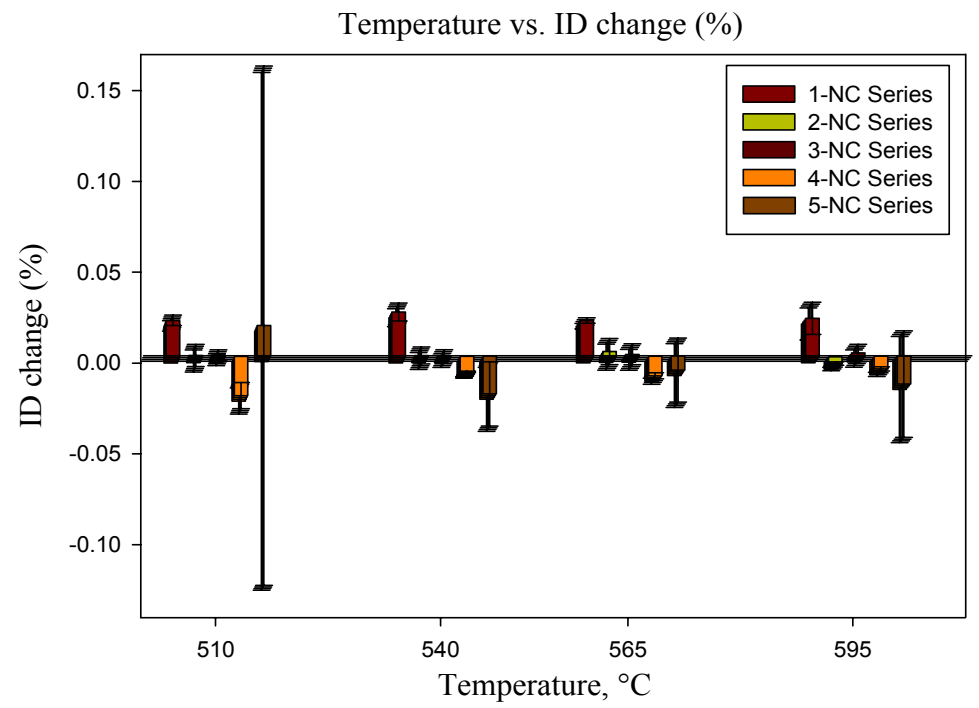

Figure 7: ID change of nitrocarburized C-rings as a function of nitrocarburizing temperature.

Table 5: $\quad$ Gap distortion of C-ring samples (unit: \%).

\begin{tabular}{|c|c|c|c|c|c|}
\hline Process & 1-NC series & 2-NC series & 3-NC series & 4-NC series & 5-NC series \\
\hline$a$ & -0.0139 & -0.1361 & -0.2644 & -0.3524 & -0.3703 \\
\hline$b$ & 0.0798 & -0.1066 & -0.2528 & -0.2367 & -0.1820 \\
\hline$c$ & 0.0311 & -0.0424 & -0.2484 & -0.2452 & -0.1893 \\
\hline$d$ & 0.0936 & -0.1173 & -0.2377 & -0.2030 & -0.1650 \\
\hline$e$ & 2.4424 & N/A & N/A & 0.0833 & -1.2482 \\
\hline
\end{tabular}

Table 5 which is a summary of the gap distortion measurements shows that the carbonitriding resulted in a larger gap distortion in the 1-NC and the 5-NC series samples than the nitrocarburizing processes. Figure 8 shows that the gap tends to close up as the C-ring thickness decreases from the 1-NC to the 5-NC series. Nitrocarburizing at $565^{\circ} \mathrm{C}$ for 5 hours led to smaller changes in gap width than other nitrocarburizing schedules.

Flatness is a geometric control in which a part surface is compared to a reference surface, usually the perfectly flat geometric counterpart of itself, to check the irregularity of the surface [17]. The flatness values in this study were 
determined by scanning approximately 2100 points along the perimeter of the Cring. The measure of flatness shows the difference between the maximum and minimum values derived from a reference surface. An example of a flatness form plot is shown in Figure 9. The small circles indicate the maximum and minimum points of deviation. The surface designated as " $1-2-3-4$ " is the plane containing the minimum point of deviation.

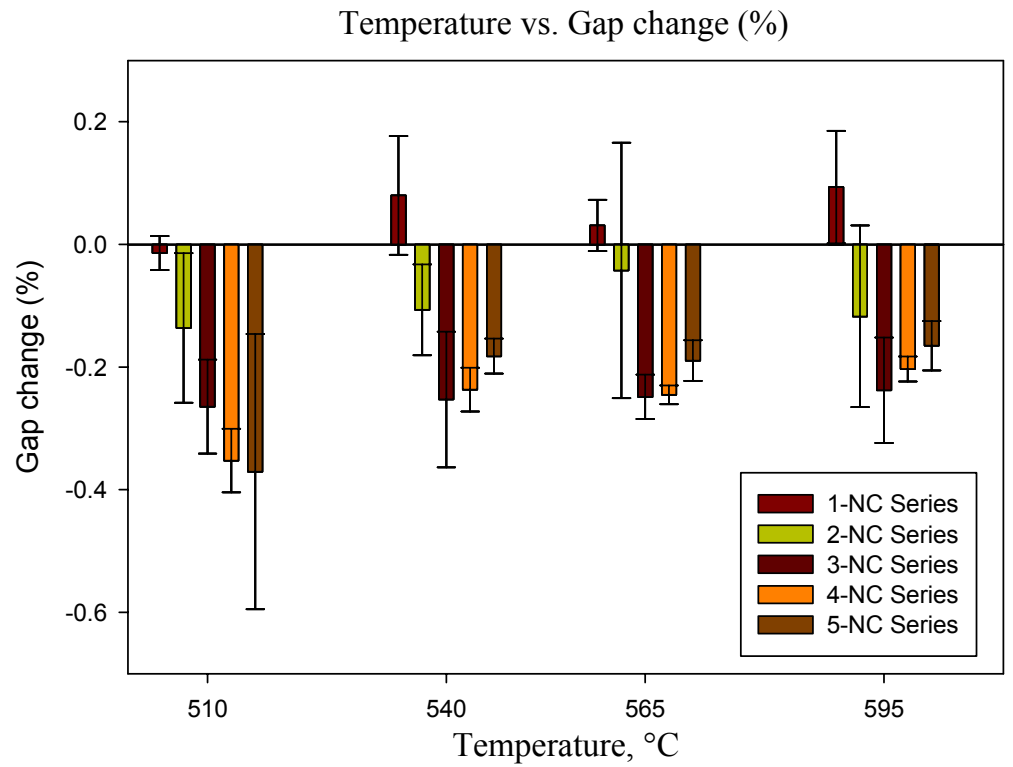

Figure 8: Gap change of nitrocarburized C-rings as a function of temperature.

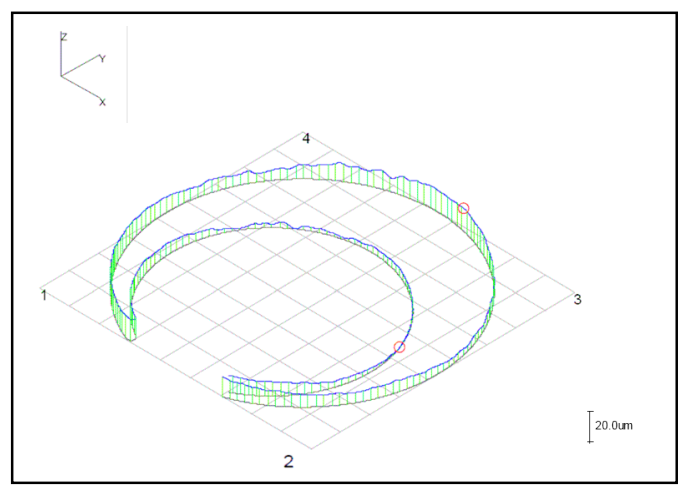

Figure 9: Flatness measurements on nitrocarburized 1-NC sample (process d). 
Table 6: $\quad$ Flatness change of C-ring samples (unit: $\mathrm{mm}$ ).

\begin{tabular}{|c|c|c|c|c|c|}
\hline Process & 1-NC series & 2-NC series & 3-NC series & 4-NC series & 5-NC series \\
\hline$a$ & -0.0045 & 0.0024 & 0.0054 & 0.0012 & 0.0002 \\
\hline$b$ & -0.0013 & 0.0021 & 0.0043 & 0.0019 & 0.0067 \\
\hline$c$ & 0.0001 & 0.0023 & 0.0023 & 0.0085 & 0.0043 \\
\hline$d$ & 0.0000 & 0.0006 & 0.0038 & 0.0050 & 0.0036 \\
\hline$e$ & -0.0038 & N/A & N/A & -0.0034 & -0.0085 \\
\hline
\end{tabular}

The values of flatness change $(\mathrm{mm})$ due to ferritic nitrocarburizing or carbonitriding are shown in Table 6. The flatness of the C-ring samples after carbonitriding was improved, which means that the difference between the maximum and minimum points of deviation was reduced compared to the sample before carbonitriding. By contrast, the nitrocarburized C-rings showed reduced flatness, except for the 1-NC series. It should be noted that the reported values of flatness are referred to the reference surface as a standard. A comparison of the flatness changes resulting from the different ferritic nitrocarburizing processes is shown in Figure 10.

Temperature vs. Flatness change ( $\mathrm{mm})$

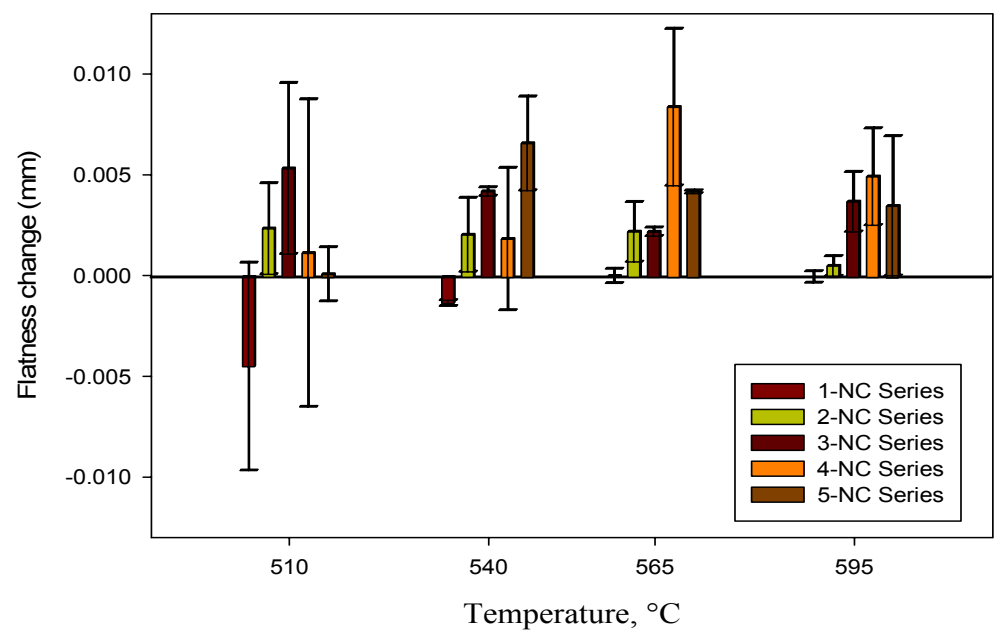

Figure 10: Flatness change of nitrocarburized C-rings as a function of nitrocarburizing temperature.

\subsection{Residual stress measurements}

The results of the residual stress measurements for the 1-NC and the 5-NC series determined by XRD are given in Table 7 . The nitrocarburizing process generated tensile residual stresses in the $\varepsilon$-nitride surface layer. This is in agreement with the findings of Kolozsva'ry [18] and Watkins et al [19]. 
Table 7: $\quad$ Residual stress analysis of C-ring samples (unit: MPa).

\begin{tabular}{|c|c|c|}
\hline \multirow{2}{*}{ Process } & \multicolumn{2}{|c|}{ Normal stress of the nitrocarburized sample } \\
\cline { 2 - 3 } & 1-NC series & 5-NC series \\
\hline$a$ & $86.2 \pm 17.2$ & $48.3 \pm 14.5$ \\
\hline$b$ & $101.4 \pm 18.6$ & $73.8 \pm 10.3$ \\
\hline$c$ & $140.0 \pm 19.3$ & $112.4 \pm 15.2$ \\
\hline$d$ & $103.4 \pm 17.9$ & $55.2 \pm 9.7$ \\
\hline
\end{tabular}

The residual stress values versus nitrocarburizing temperatures for the 1-NC and the 5-NC series are plotted in Figure 11. The magnitude of the residual stress tends to increase with increasing nitrocarburizing temperature, reaching a maximum value at about $565^{\circ} \mathrm{C}$. The main causes of the residual stresses in the compound layer are related to the volume changes during the formation of different phases and the internal stresses produced by molecular nitrogen formation within the porosity. The carbon level in the compound layer also has a significant effect on residual stress with increased carbon content producing an increased residual stress level [18]. The other point to be noted is that the residual stresses are lower for the thinner C-ring specimens (5-NC series) compared to the thicker specimens (1-NC series).

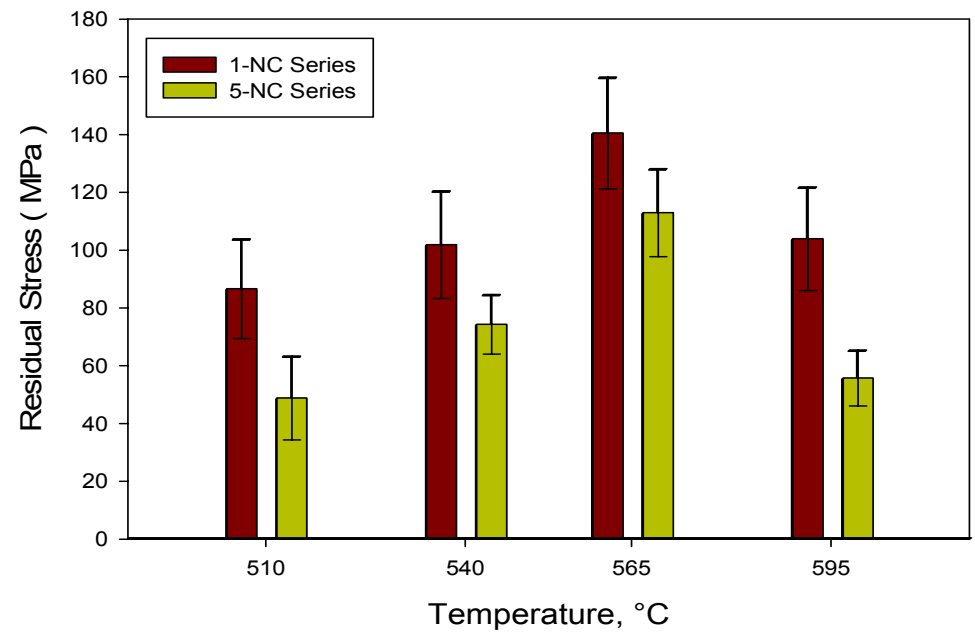

Figure 11: Plot of the residual stress changes in the C-ring samples.

The residual stresses together with the depth of the compound layer for the 5$\mathrm{NC}$ series are plotted as a function of nitrocarburizing temperature (processes $a$, $b, c$ and $d$ ), in Figure 12. As the compound layer thickness decreases, the residual stress increases. The thinner layers exhibited higher residual stress values, which may be predominantly due to the more compact nature of the thinner compound layers, and a minor effect of the complex influence of the 
relaxation process during the long heat treating cycle [18]. The thickness of the compound layer is dependent on the temperature, atmosphere composition, steel grade and heat treatment time [6,20]. Compared to the samples nitrocarburized at $510{ }^{\circ} \mathrm{C}$ and $540{ }^{\circ} \mathrm{C}$, the thickness of the compound layer is smaller in the samples nitrocarburized at $565^{\circ} \mathrm{C}$ and $595{ }^{\circ} \mathrm{C}$. This is, in part, due to the shorter heat treatment times.

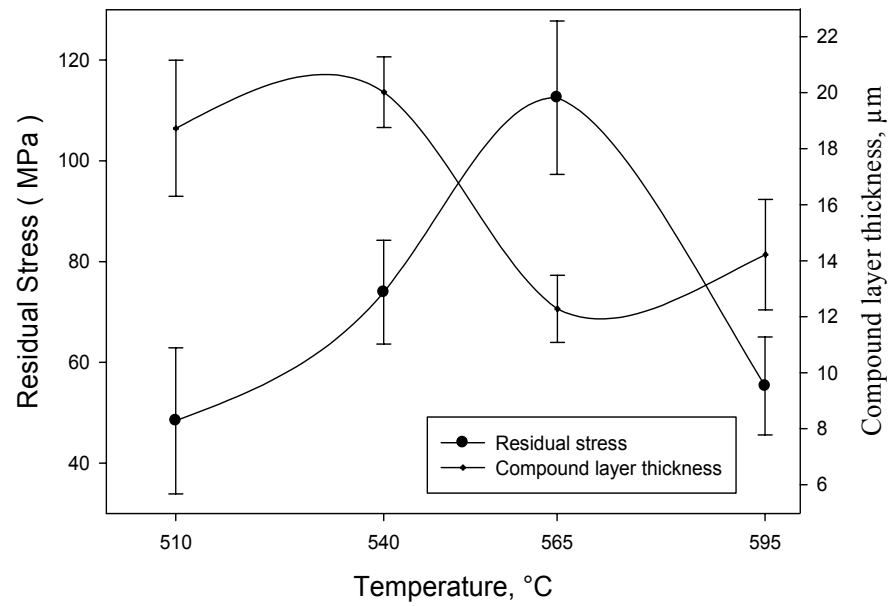

Figure 12: Comparison of the effect of nitrocarburizing temperature on the residual stresses and compound layer thicknesses for the 5-NCCring samples.

\section{Conclusions}

1. A comparison between the ferritic nitrocarburizing and carbonitriding processes based on the variable thickness of the C-ring samples indicates that:

- In comparison with nitrocarburizing, gas carbonitriding resulted in the largest OD distortion in the 1-NC series; the largest ID changes in the 1-NC, 4$\mathrm{NC}$ and 5-NC series; the largest gap distortion in the 1-NC and 5-NC series.

- The smaller dimensional changes associated with the nitrocarburizing process are attributed to the low heat treatment temperatures which are in the ferritic phase region where no transformation from austenite to martensite occurs.

2. The combination of nitrocarburizing temperature and time as well as the varying thickness of the $\mathrm{C}$-rings lead to different size and shape distortions.

- Ferritic nitrocarburizing resulted in a small expansion of the OD dimension in all C-ring samples.

- Ferritic nitrocarburizing produced either a small contraction or small expansion in ID depending on temperature-time and specimen thickness. The thinner specimens, 5-NC and 4-NC series, generally exhibited a contraction in ID. 
- The gap tends to close up as the thickness decreases from the 1-NC to the 5 -NC series.

3. Ferritic nitrocarburizing imparted tensile residual stresses in the $\varepsilon$-nitride surface layers of the C-ring samples.

- A thinner compound ( $\varepsilon$-nitride) layer gave rise to higher residual stress values.

- The tensile residual stresses in the $\varepsilon$-nitride layer were higher in the thicker (1-NC series) than the thinner (5-NC series) specimens.

4. The size and shape distortions can be reduced by choosing appropriate nitrocarburizing parameters. A combination of $565^{\circ} \mathrm{C}$ and 5 hours led to smaller changes in OD, ID and gap, but the largest tensile residual stresses in the $\varepsilon$ nitride surface layers.

\section{References}

[1] American Society for Metals Committee on Gas Carburizing, Carburizing and Carbonitriding, American Society for Metals: Metals Park, Ohio, pp. 1-5, 1977.

[2] Davis, J.R., Carbonitriding (Chapter 5). Surface Hardening of Steels: Understanding the Basics, ed. J.R. Davis, ASM International, Materials Park, Ohio, pp. 127-134, 2002.

[3] Dossett, J., Carbonitriding. ASM Handbook, Heat Treating, 4, ASM International, Materials Park, Ohio, pp. 376-384, 1991.

[4] Krauss, G., Steels: Processing, Structure, and Performance, ASM International, Metals Park, Ohio, pp. 456-460, 2005.

[5] Bell, T., Gaseous and plasma nitrocarburizing. ASM Handbook, Heat Treating, 4, ASM International, Materials Park, Ohio, pp. 425-436, 1991.

[6] Pye, D., Practical Nitriding and Ferritic Nitrocarburizing, ASM International, Materials Park, Ohio, pp. 193-194, 201-202, 2003.

[7] Çelik, A., Karakan, M., Alsaran, A. \& Efeoglu, I., The investigation of structural, mechanical and tribological properties of plasma nitrocarburized AISI 1020 steel. Surface and Coatings Technology, 200(5-6), pp. 19261932, 2005.

[8] Davis, J.R., Nitrocarburizing (Chapter 7). Surface Hardening of Steels: Understanding the Basics, ed. J.R. Davis, ASM International, Materials Park, Ohio, pp. 195-212, 2002.

[9] Wells, A., Metallographic analysis of compound layers on ferritic nitrocarburized plain low carbon steel. Materials Science, 20, pp. 24392445, 1985.

[10] Dawes, C., Nitrocarburising and its influence on design in the automotive sector. Heat Treatment of Metals, 1, pp. 19-30, 1990.

[11] Schobesberger, P., Streng, T. \& Abbas, S., Low-Distortion Heat Treatment of Thin Parts, Industrial Heating, 69(2), pp. 30-34, 2002.

[12] Boyle, E., Bowers, R.J. \& Northwood, D.O., The use of Navy C-ring specimens to investigate the effects of initial microstructure and heat treatment on the residual stress, retained austenite, and distortion of 
carburized automotive steels. SAE Transactions: Materials and Manufacturing, 116(5), pp. 253- 261, 2007.

[13] Ruud, C., Measurement of residual stresses, Handbook of Residual Stress and Deformation of Steel, eds. G. Totten, M. Howes, \& T. Inoue, ASM International, Materials Park, Ohio, pp. 99-115, 2002.

[14] Pineault, J.A., Belassel, M. \& Brauss, M.E., X-ray diffraction residual stress measurement in failure analysis. ASM Handbook, Failure Analysis and Prevention. 11, ASM International, Materials Park, Ohio, pp. 484-497, 2002.

[15] ASTM E915-96 standard test method for verifying the alignment of X-ray diffraction instrumentation for residual stress measurement, American Society for Testing and Materials, ASTM International: West Conshohocken, PA, 2002.

[16] Walton, H.W., Deflection methods to estimate residual stress, Handbook of Residual Stress and Deformation of Steel, eds. G. Totten, M. Howes \& T. Inoue, ASM International, Materials Park, Ohio, pp. 89-98, 2002.

[17] Meadows, J.D., Geometric Dimensioning and Tolerancing: Applications and Techniques for Use in Design, Manufacturing, and Inspection, CRC Press, 1995.

[18] Kolozsva'ry, Z., Residual stress in nitriding, Handbook of Residual Stress and Deformation of Steel, eds. G. Totten, M. Howes \& T. Inoue, ASM International, Materials Park, Ohio, pp. 209-219, 2002.

[19] Watkins, T.R., England, R.D., Klepser, C. \& Jayaraman, N., Measurement and analysis of residual stress in $\varepsilon$-phase iron nitride layers as a function of depth, Advances in X-ray Analysis, 43, pp. 31-38, 2000.

[20] Sproge, L. \& Midea, S.J., Analysis and control of nitriding and nitrocarburizing atmospheres. Proc. of the $2^{\text {nd }}$ Int. Conf. On Carburizing and Nitriding with Atmospheres, eds. J. E. Morral, J. Grosch \& M. Schneider, Elsevier: Cleveland, Ohio, 1995. 